\title{
RNA-based disease control as a complementary measure to fight Fusarium fungi through silencing of the azole target Cytochrome P450 Lanosterol C-14 $\alpha$-Demethylase
}

\author{
Aline Koch • Elke Stein • Karl-Heinz Kogel $(\mathbb{D}$
}

Accepted: 1 June 2018 / Published online: 23 June 2018

(C) The Author(s) 2018

\begin{abstract}
RNA-based disease control has shown great potential for controlling pest and diseases in crop plants. While delivery of inhibitory noncoding double-stranded (ds)RNA by transgenic expression is a promising concept, it requires the generation of transgenic crop plants, which may cause substantial delay for application strategies depending on the transformability and genetic stability of the crop plant species. Focusing on agronomic important barley - Fusarium spec. pathosystems, we have sought for alternative strategies to apply dsRNAs for fungal control. Recently, we have demonstrated that a spray application of a long noncoding dsRNA termed CYP3RNA, which targets the three fungal Cytochrome P450 lanosterol C-14 $\alpha$-demethylase genes FgCYP51A, $\mathrm{FgCYP} 51 \mathrm{~B}$, and FgCYP51C, inhibits Fusarium graminearum $(F g)$ on barley leaves (Koch et al., PLoS Pathogens, 12, e1005901, 2016). Here we show that another Fusarium species, F. culmorum $(F c)$, also is sensitive to CYP51-derived dsRNAs. Treating $F C$ with various dsRNAs targeting the genes $F C C Y P 51 A$, $F_{C} C Y P 51 B$ and $F_{C} C Y P 51 C$ was destructive to the fungus and resulted in growth retardation in in vitro cultures. We discuss important consequences of this finding on
\end{abstract}

Electronic supplementary material The online version of this article (https://doi.org/10.1007/s10658-018-1518-4) contains supplementary material, which is available to authorized users.

A. Koch · E. Stein · K.-H. Kogel $(\bowtie)$

Institute of Phytopathology, Centre for BioSystems, Land Use and Nutrition, Justus Liebig University, Heinrich-Buff-Ring 26-32,

D-35392 Giessen, Germany

e-mail: karl-heinz.kogel@agrar.uni-giessen.de future RNA-based disease control strategies. Given the ease of design, high specificity, and applicability to diverse pathogens, the use of target-specific dsRNA as an anti-fungal agent offers unprecedented potential for novel plant protection strategies.

Keywords Azole · Double-stranded RNA · Fusarium • Host-induced gene silencing (HIGS) · RNA interference · Spray-induced gene silencing (SIGS) · Small RNA

\section{Introduction}

To meet the increasing food and energy demands of a growing population, it will be necessary to roughly double crop yields worldwide over the next 40-50 years despite a changing climate (FAO 2012; FAO 2013). Meeting this challenge will require developing groundbreaking strategies that promote sustainable plant production. Recent discoveries that animals and plants can deliver small (s)RNAs into interacting organisms thereby targeting their virulence functions has opened up new avenues for disease control (for recent reviews see Weiberg et al. 2015; Guo et al. 2016; Cai et al. 2018): A recent breakthrough study has shown that pathogenderived sRNAs can move into host cells to suppress host immunity (Weiberg et al. 2013). The grey mold pathogen Botrytis cinerea $(B c)$ produces sRNA effectors, which can migrate into and down-regulate Arabidopsis and tomato genes involved in disease resistance. Some sRNA effectors can target multiple host defence genes to enhance $B c$ pathogenicity. For example, Bc-siR37 
suppresses host immunity by targeting at least 15 Arabidopsis genes, including WRKY transcription factors, receptor-like kinases, and cell wall-modifying enzymes (Wang et al. 2017a). $B c$ sRNAs utilize the host RNAi machinery by binding to Arabidopsis ARGONAUTE1 (AGO1) to silence host defense genes. Consistent with this finding, $B c$ causes less disease symptoms on the Arabidopsis ago1-27 mutant compared to wild type (wt) plants. Similarly, the ago 1-27 mutant is more resistant to the pathogenic ascomycete Verticillium dahliae $(V d)$, which causes Verticillium wilt disease on many plants, suggesting $V d$ also uses sRNAs to silence host target genes. Moreover, one of the most destructive pathogens of wheat Puccinia striiformis $(P s)$ also delivers fungal sRNAs, such as microRNA-like RNA1 (milR1) into host cells and suppresses wheat Pathogenesis-related $2(P R-2)$ in the defense pathway. Silencing of the $P s$ milR1 precursor led to enhanced wheat resistance to the virulent $P s$ isolate (Wang et al. 2017b).

Significant for agriculture, recent reports show that animals and plants deliver host sRNAs into interacting microbes to suppress their virulence (Zhang et al. 2016). $V d$ recovered from infected cotton plants, contained 28 different sRNA that matched miRNAs from cotton, implying that host-derived sRNAs were transmitted into the pathogen during infection. Two of these cotton miRNAs, miR166 and miR159, target the fungal genes $\mathrm{Ca}^{2+-}$ dependent cysteine protease calpain (VdClp-1) and Iso-trichodermin C-15 hydroxylase (VdHiC-15), respectively. Consistent with host-mediated silencing, $V d C l p-1$ and $V d H i C-15$ transcripts were reduced in the $V d$ hyphae recovered from $V d$-infected cotton. Moreover, the fungal mutants $v d c l p-1$ and $v d h i c-15$ were reduced in virulence, confirming that these genes contribute to pathogenicity. Animal hosts also export sRNAs into interacting parasite cells to suppress their virulence (LaMonte et al. 2012). Sickle cell erythrocytes of anemia patients accumulate higher levels of miR-451 and lethal-7i (let-7i), which are transferred into the parasite Plasmodium falciparum.

Strongly supporting the concept that hosts and their interacting microbes/pests have co-evolved dedicated strategies to communicate with each other through sRNA, delivery of designer sRNA from plant hosts into an interacting target microbe/pest has been frequently demonstrated. Such engineered RNA-based targeted gene silencing has emerged as a promising strategy for crop protection. A wide range of transgenic crops expressing dsRNAs that are subsequently processed into sRNAs targeting essential and/or pathogenicity genes are more resistant to viruses, viroids, bacteria, fungi, oomycetes, nematodes, and insects (Cai et al. 2018). Several studies demonstrated that cereals can be protected from Fusarium species by expressing dsRNAs targeting essential fungal genes such as Chitin synthases, $\beta-1,3-G l u c a n$ synthase, or the azole fungicide target Cytochrome P450 lanosterol C-14 $\alpha$-demethylase (Koch et al. 2013; Cheng et al. 2015; Chen et al. 2016). Moreover, banana could be protected from Fusarium wilt caused by the soilborne fungus Fusarium oxysporum f. sp. cubense (Ghag et al. 2014). Remarkably, RNA-based strategies have also been discussed in the context of the control of mycotoxin contamination in crop plants (Majumdar et al. 2017). The broad applicability of the technique supports a basic evolutionary-conserved mechanism of sRNA trafficking.

Microbial pathogens and pests, in contrast to mammals, are amenable to environmental sRNA, meaning that they can take up noncoding RNAs from the environment, whereby these RNAs maintain their RNAi activity. This knowledge raises the possibility that plants can be protected from pathogens/pests by exogenously supplied RNA (Wang et al. 2016; Koch et al. 2016). Possible agronomic application of environmental RNA is affirmed by the high sensitivity of Fusarium graminearum $(\mathrm{Fg})$ to dsRNAs and siRNAs (Koch et al. 2016). In support of this notion, spraying a $791 \mathrm{nt}$ long noncoding dsRNA (CYP3RNA), which targets the three Cytochrome P450 lanosterol C-14 $\alpha$ demethylase (CYP51) genes FgCYP51A, FgCYP51B and $\mathrm{FgCYP} 5 \mathrm{CC}$ of $\mathrm{Fg}$ strongly inhibited fungal growth on barley leaves. Strikingly, and consistent with the knowledge that sRNA is mobile (Molnar et al. 2010; Melnyk et al. 2011; Mermigka et al. 2016), compromised fungal growth was observed in the directly sprayed (local) as well as the non-sprayed (distal) parts of detached leaves. Efficient spray-induced gene silencing (SIGS) in the distal tissue required: $i$. passage of CYP3RNA via the plant vascular system, $i i$. uptake into the interacting fungus, and iii. processing into siRNAs by fungal FgDcl-1 (Koch et al. 2016).

Importantly, application of CYP3RNA to liquid in vitro cultures of $\mathrm{Fg}$ inhibited mycelial growth, suggesting that in vitro screenings could be used to explore novel dsRNAs and their fungal targets (Koch et al. 2013, 2016; Koch and Kogel 2014). 
Here we show that $F c C Y P 51$-derived dsRNAs also inhibit $F$. culmorum $(F C)$ in in vitro cultures showing that Fusarium cultures are amenable to fast dsRNAs screenings.

\section{Results and discussion}

Exploiting the recent discovery of bidirectional communication between a host and its microbial interactor via RNAs (Weiberg et al. 2013; Zhang et al. 2016), delivery of artificial dsRNAs or sRNAs by transgenic expression (Fig. 1a) or spray application (Fig. 1b) has the potential to become an efficient disease control method. Direct application of dsRNAs or sRNAs onto host plants or post-harvest products circumvents transgenic approaches, leading to silencing of the target microbe/ pest gene and efficient disease control (Wang et al. 2016; Koch et al. 2016; Niehl et al. 2018). Here we addressed the question whether Fusarium species other than $\mathrm{Fg}$ are sensitive to dsRNA derived from homologous fungal CYP51 genes. To this end, we used custom- made dsRNAs deduced from the $F_{C}$ genes $F_{C} C Y P 51 A$ (Fc-CYPA-I; Fc-CYPA-II), FcCYP51B (Fc-CYPB-I; Fc-CYB-II) and $F c C Y P 51 C$ (Fc-CYPC-I; Fc-CYPCII) (Fig. S1). These dsRNAs were tested in fungal liquid in vitro cultures. Macroconidia of $F_{C}$ strain KF350 were incubated in microtiter plates in $100 \mu \mathrm{L}$ TE buffer (5 $\mu \mathrm{M}$ TRIS, $0.5 \mu \mathrm{M}$ EDTA, pH 7) containing $20 \mathrm{ng} \mu \mathrm{L}^{-1}$ dsRNA. After $48 \mathrm{~h}$, the amount of mycelium was quantified indirectly using the MTT method which records cell metabolic activity (Berridge and Tan 1993). The method is indicative of cell viability and can be used to quantify the inhibitory effects of dsRNAs in in vitro cultures. Except Fc-CYPA-II, virtually all CYP51-dsRNAs reduced the formation of formazan from thiazolyl blue tetrazolium bromide compared to a GUS-dsRNA control (Fig. 2). Strong effects (significance $p \leq 0.05$; $t$-test) were observed for all the dsRNAs targeting the $F_{C} C Y P 51 B$ and the $F_{C} C Y P 51 C$ gene. dsRNA Fc-CYPB-I showed strongest activity with a $39 \%$ reduction of the amount of living mycelium. These results are consistent with previous reports showing that

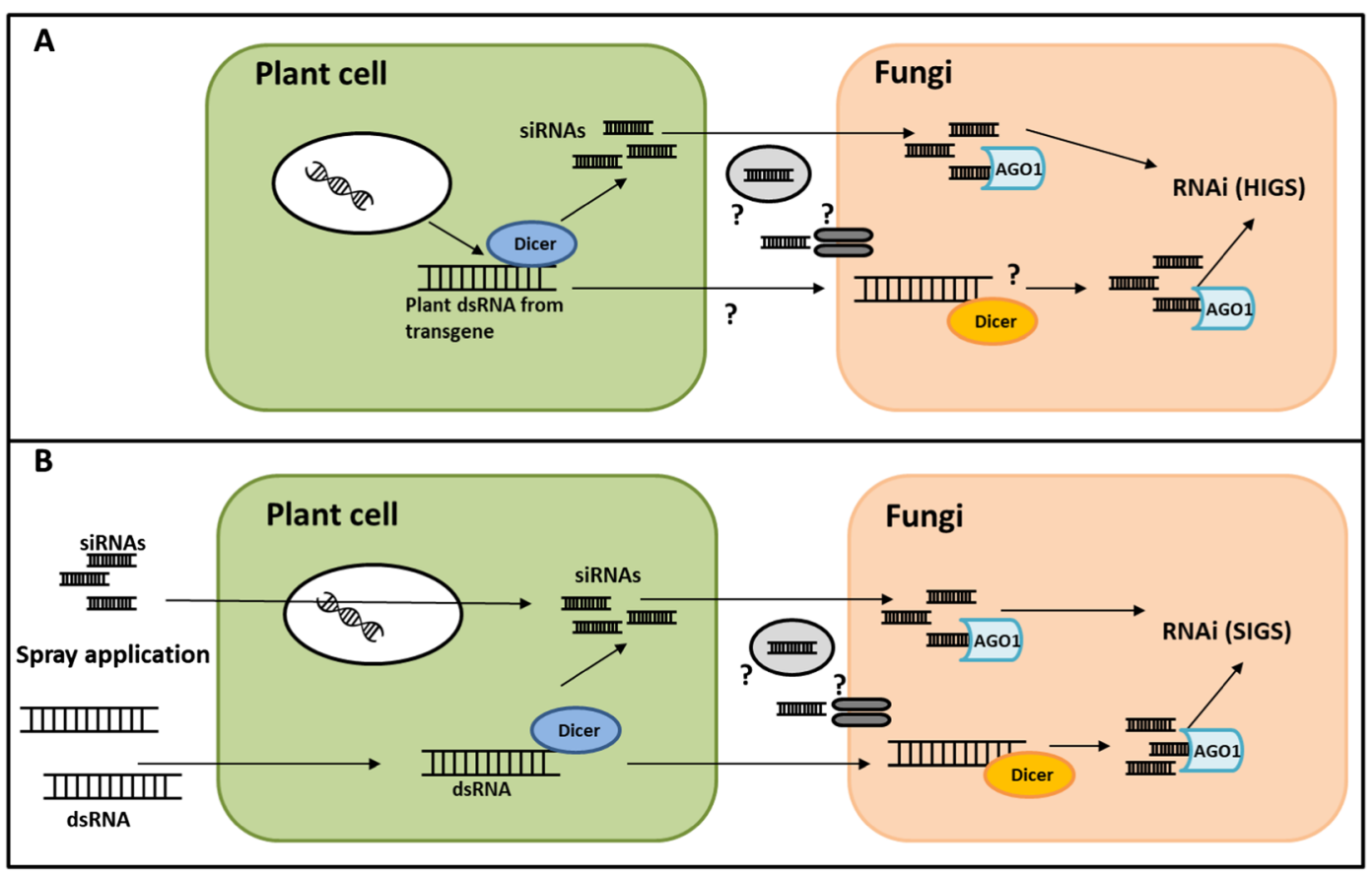

Fig. 1 Possible transfer routes and molecules in host-induced gene silencing (HIGS) and spray-induced gene silencing (SIGS) of fungal target genes. a A transgene-derived dsRNA is produced and processed by the ribonuclease (RNase) III enzyme DICER in the plant cell. Whether the precursor itself and/or the resulting siRNA is transported into the fungus, where the precursor could also be processed by the fungal RNAi machinery, is unclear. b Sprayed dsRNAs are taken up via unknown mechanisms by the plant and processed into siRNAs. Both the precursor dsRNA and the resulting siRNAs can be taken up by the fungus (Koch et al. 2016). Possible transfer routes for both mechanisms via vesicles or RNA-transporters are indicated. AGO1 seems to be essential for the RNAi response in Fusarium (Chen et al. 2015) 


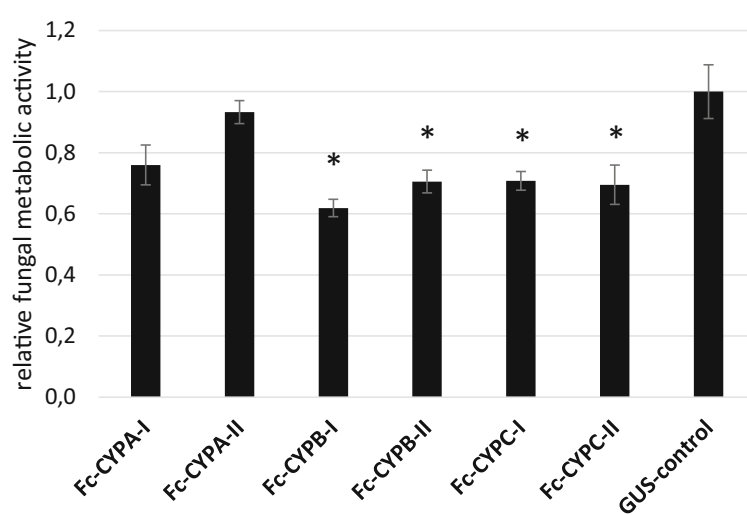

Fig. 2 Relative $F$. culmorum growth in in vitro liquid culture as measured by the MTT viability assay after treatment with CYP51-dsRNAs. A macroconidia suspension $(100 \mu \mathrm{l}$ of TE buffer ( $5 \mu \mathrm{M}$ TRIS, $0.5 \mu \mathrm{M}$ EDTA) containing 300 macroconidia of $F c$ in Czapek Dox medium was incubated in 96-well plates for $48 \mathrm{~h}$ at RT with $2 \mu \mathrm{g}$ dsRNA. dsRNA generated from the GUS gene was used as control. The assay was performed by adding $50 \mu \mathrm{l}$ RPMI media followed by incubation for $3 \mathrm{~h}$ at $37^{\circ} \mathrm{C}$. The amount of formazan was assessed by resuspension in isopropanol and measurement of the optical density (OD) at $595 \mathrm{~nm}$. Error bars represent standard deviation (SD) of three independent experiments. Asterisks indicate statistical significance $(* p<0.05$; students $t$-test)

FgCYP51B is most important for ergosterol biosynthesis and thus survival of the fungus (Fan et al. 2013; Liu et al. 2011; Machado et al. 2018).

To further confirm a correlation between reduced fungal growth and silencing of target genes, we measured the expression of the three FcCYP51 genes by quantitative real-time PCR (qRT-PCR). Treatment of fungal cultures with CYP51-dsRNA resulted in downregulation of the respective target genes $F_{C} C Y P 51 A$, $F_{C} C Y P 51 B$ and $F_{C} C Y P 51 C$ : Fc-CYPA-I/II reduced $F g C Y P 51 A$ expression by 60 to $80 \%$, Fc-CYPB-I/II reduced $F C C Y P 51 B$ expression by approximately $40 \%$, and $\mathrm{Fc}-\mathrm{CYPC}-\mathrm{I} / \mathrm{II}$ reduced $\mathrm{FcCYP51C}$ by more than 95\% (Fig. 3). Comparing the expression data with data of the MTT assay, it can be concluded that the strength of silencing of FcCYP51 genes does not directly correlate with growth retardation. For instance, strong silencing of $F c C Y P 51 A$ expression does not lead to stronger fungal inhibition than silencing of $F_{C} C Y P 51 B$ by $40 \%$. In accordance with Fan et al. (2013), the data further support the requirement of CYP51B and CYP51C but not CYP51A for Fusarium development and survival. Consistent with this notion, ANOVA analysis confirmed a significant difference in fungal metabolic activity when targeting $F_{C} C Y P 51 A$ vs. FcCYP51B or FcCYP51C (null hypothesis confirmed $p=0.008$ ), but there was no

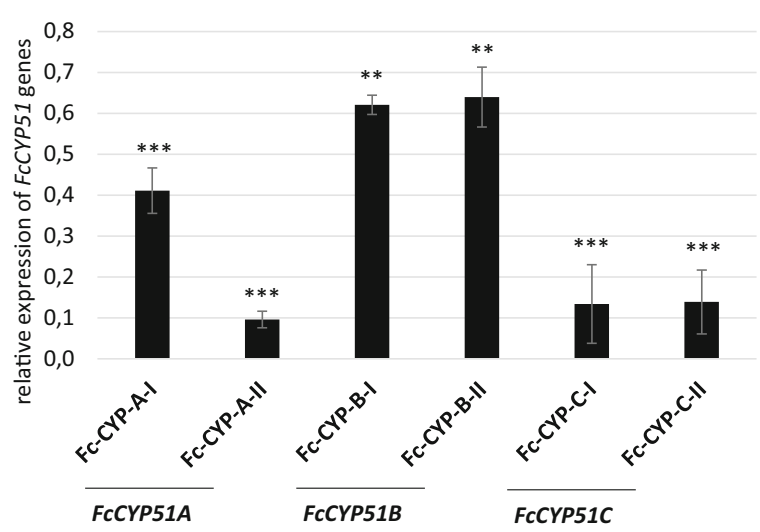

Fig. 3 Silencing of $F c C Y P 51$ genes in in vitro liquid cultures of F. culmorum after treatment with CYP51-dsRNA. A suspension $(100 \mu \mathrm{l})$ containing 300,000 macroconidia $\mathrm{ml}^{-1}$ of $F_{C}$ in Czapek Dox medium was incubated in 96-well plates for $48 \mathrm{~h}$ at RT with $2 \mu \mathrm{g}$ dsRNA. cDNA was generated after total RNA extraction from in vitro cultures. Gene-specific expression of $F c C Y P 51 A, F c C Y P 51 B$ and $F c C Y P 51 C$ was measured by qRTPCR and normalized to fungal $E F 1-\alpha$ (FGSG_08811) as reference gene. Error bars represent SE of three independent experiments. Asterisks indicate statistical significance $(* * p<0.01$; $* * * p<0.001$ students $t$-test)

difference in metabolic activity of GUS-dsRNA control vs. CYP51A dsRNAs treated cultures (null hypothesis of a difference falsified; $p=0.095)$. Notably, single CYP51-dsRNAs also affected the expression of respective non-target $F_{C} C Y P 51$ genes, suggesting coregulatory effects (Fig. S2): FCCYP51A was cosuppressed by Fc-CYPB-II, Fc-CYPC-I and FcCYPCII, and $F c C Y P 51 C$ was co-suppressed by Fc-CYPA-I, Fc-CYPB-I and Fc-CYPB-II, while FcCYPA-II unexpectedly induced the expression of $F_{C} C Y P 51 B$ and $F C C Y P 51 C$. More research is required to explain gene co-induction mechanistically.

Fungal cultures treated with CYP51-dsRNAs also showed weak aberrant morphologies of hyphae such as undulated, slightly conglomerated and more branched hyphae with defective septation, as compared to treatments with GUS-dsRNA (Fig. 4). These data together show that, like $F$. graminearum, also F. culmorum is sensitive to dsRNA treatments. Despite the fact that aberrant phenotypes in in vitro screening of $F$. graminearum with dsRNA were less obvious than in HIGS and SIGS approaches (Koch et al. 2016), in vitro activity of candidate dsRNAs is a proxy for their efficiency in spray experiments and transgenic plants. Especially the straightforwardness of these screenings, cost efficiency and rapidity argue for future application in pre-screens. Moreover, our work further supports the 
Fig. 4 Microscopic analysis of $F$. culmorum growth in liquid culture after treatment with various Fc-CYP51 dsRNAs. A conidia suspension $(100 \mu \mathrm{l})$ containing 3000 conidia ml ${ }^{-1}$ of F. culmorum KF350 in Czapek Dox medium was incubated in 96-well plates for $48 \mathrm{~h}$ at RT (Koch et al. 2016). GUS-dsRNA was used as negative control.
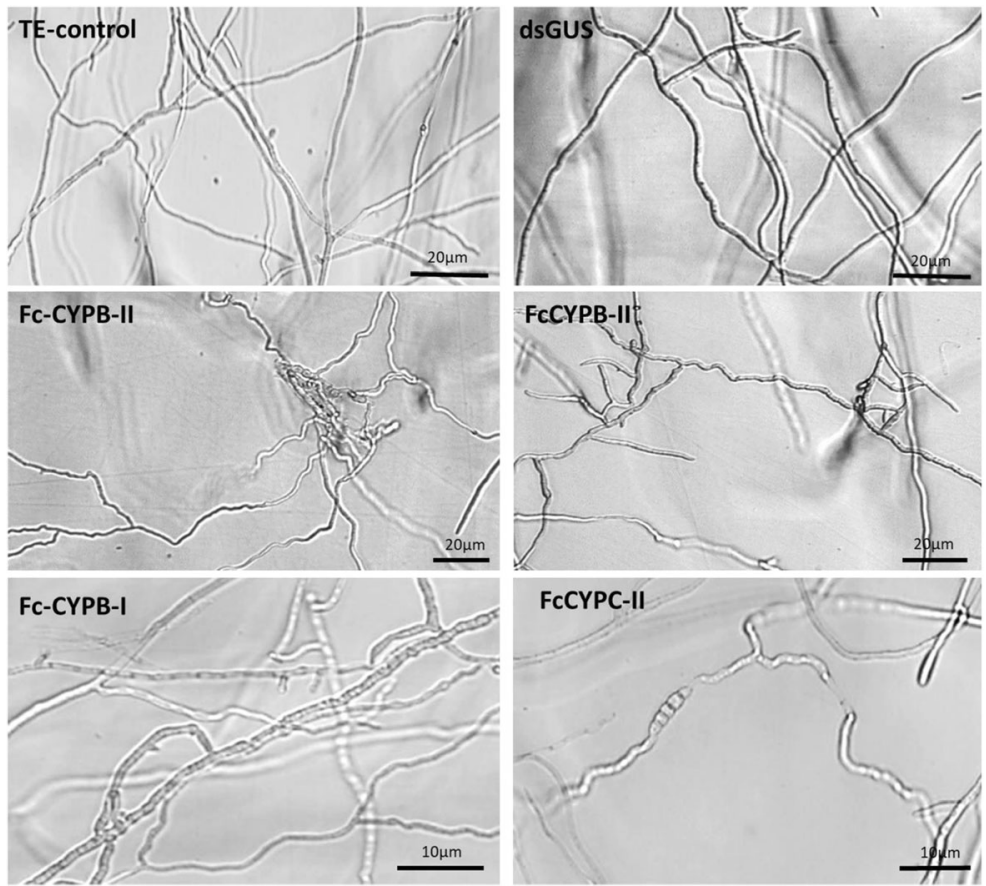

notion that Fusarium species are amenable to RNAbased disease control strategies and that HIGS and SIGS setups are highly efficient to control necrotrophic fungi of the genus Fusarium on cereal plants. Clearly, more research is required to address open questions related to the use of RNA in plant protection. For instance, it is yet unresolved whether dsRNA in general activates immune responses in plants: dsRNAs purified from virus-infected plants and the dsRNA analog polyinosinic-polycytidylic acid (poly(I:C)) induced typical pattern-triggered immunity (PTI) responses dependent on the co-receptor SOMATIC EMBRYOGENESIS RECEPTOR-LIKE KINASE 1 (SERK1), but independent of DICERlike in Arabidopsis. Moreover, dsRNA treatment of Arabidopsis induces SERK1-dependent antiviral resistance (Niehl et al. 2016). On the other hand, CYP3RNA did not induce marker genes of the salicylate and jasmonate pathways in barley leaves, indicating that the immunogenic activity of dsRNA in plants is still an open question.

A recent study reported that miRNAs from plants may be taken up by humans and thus may affect target genes (Zhang et al. 2012). While the idea that nutrition may encompass the ingestion of genetic information is fascinating, careful replication of these striking results is necessary. Emerging evidence suggests that the initial claims of delivery and effect of foreign dietary genetic information in mammals may prove to be overstated. Nonetheless, the scientific community must be careful not to dismiss prematurely the concept of dietary transfer of genetic information (Sarkies and Miska 2013; Witwer and Hirschi 2014).

\section{Materials and methods}

Fungal material

Fusarium culmorum strain KF350 (Deshmukh and Kogel 2007) was cultured on potato dextrose agar (PDA). Preparation of fungal inoculum was performed as described (Koch et al. 2016).

\section{CYP51-dsRNAs production}

Fc-CYPA-I, Fc-CYPA-II, Fc-CYPB-I, Fc-CYPB-II, FcCYPC-I, Fc-CYPC-II dsRNA sequences (see Fig. S1) derived from the previously published genes FCCYP51A, FCCYP51B, and FCCYP51C (NCBI data base). GUS-dsRNA was derived from the $\beta$-Glucuronidase (GUS) gene. All dsRNAs were ordered from Eupheria Biotech GmbH (Dresden, Germany) and stored at $-80^{\circ} \mathrm{C}$. 
Table 1 Primers

\begin{tabular}{lll}
\hline Primer name & Primer sequence & Target gene \\
\hline CYP51A4_F & CCT TTG GTG CCG GTA GAC AT & qPCR, silencing CYP51A \\
CYP51A4_R & CCC ATC GAA TAA ACG CAG GC & \\
QCYP51B_F & TCT ACA CCG TTC TCA CTA CTC C & qPCR, silencing CYP51B \\
QCYP51B_R & GCT TCT CTT GAA GTA ATC GC & \\
CYP51C2_F & CGA GTC CCT GGC ACT GAA TG & qPCR, silencing CYP51C \\
CYP51C2_R & GCT CAT CAC CCC AAA ACC GT & \\
EF1a_F & CAAGGCCGTCGAGAAGTCCAC & qPCR, reference gene elongation factor 1a \\
EF1a_R & TGCCAACATGATCATTTCGTCGTA & \\
\hline
\end{tabular}

In vitro assay, microscopy and MTT assay

For microscopic evaluation, $100 \mu \mathrm{l}$ of $F c$ conidia suspension in Czapek Dox media buffered with $5 \mu \mathrm{M}$ TRIS/0.5 $\mu \mathrm{M}$ EDTA, pH 7.0 (final concentration) containing 300 spores and $2 \mu \mathrm{g}$ CYP51-dsRNA were incubated in 96-well plates. dsRNA derived from the GUS gene and Tris-EDTA (TE)-buffer were used as controls. Pictures were taken after $48 \mathrm{~h}$ of incubation at room temperature (RT) with a LEICA DFC300 FX light microscope. For the determination of fungal viability after in vitro incubation with dsRNAs, the MTT (3-(4,5-dimethylthiazol-2-yl)-2,5-diphenyltetrazolium bromide) tetrazolium reduction assays was performed. After $48 \mathrm{~h}$ of incubation with dsRNAs, $50 \mu \mathrm{l}$ RPMI (Roswell Park Memorial Institute) medium containing $0.1 \mathrm{mg} \mathrm{ml}^{-1}$ thiazolyl blue tetrazolium bromid (Sigma) was added to the wells and incubated for $3 \mathrm{~h}$ at $37{ }^{\circ} \mathrm{C}$. Liquid was removed carefully by pipetting before the formed formazan was resuspended in $100 \mu \mathrm{l}$ isopropanol containing $5 \% \mathrm{HCl}$. The quantity of formazan was determined by measuring the optical density at $595 \mathrm{~nm}$. Values are directly proportional to the number of viable cells (Berridge and Tan 1993).

Fungal transcript analysis

To assess silencing of the FcCYP51 genes, mRNA expression analysis was performed using qRT-PCR. RNA extraction from in vitro cultures was performed with GENEzol (Geneaid) following the manufacturer's instructions. Freshly extracted mRNA was used for cDNA synthesis using qScript ${ }^{\mathrm{TM}}$ cDNA kit (Quantabio). For qRT-PCR, $10 \mathrm{ng}$ of cDNA was used as template in the QuantStudio 5 Real-Time PCR system (Applied Biosystems). Amplifications were performed in $7.5 \mu \mathrm{l}$ of SYBR $®$ green JumpStart Taq ReadyMix (SigmaAldrich) with 5 pmol oligonucleotides. Each sample had three technical repetitions. Primers were used for studying expression of CYP51 genes with reference to Elongation factor 1-alpha (EF1-a) gene (FGSG_08811) (Table 1). After an initial activation step at $95^{\circ} \mathrm{C}$ for $5 \mathrm{~min}, 40$ cycles $\left(95^{\circ} \mathrm{C}\right.$ for $30 \mathrm{~s}, 57^{\circ} \mathrm{C}$ for $30 \mathrm{~s}, 72^{\circ} \mathrm{C}$ for $30 \mathrm{~s}$ ) were performed. $\mathrm{Ct}$ values were determined with the 7500 Fast software supplied with the instrument. Levels of CYP51 transcripts were determined via the 2- $\Delta \Delta$ Ct method (Livak and Schmittgen 2001) by normalizing the amount of target transcript to the amount of the reference transcript $E F 1-a$.

Statistical analysis

For statistical analysis, two-tailed students $t$-tests were performed with data gained in in vitro assays and qRTPCR. ANOVA was used to analyze the differences in metabolic activity of fungal cultures treated with different $F c C Y P 51$-targeting dsRNA probes.

Acknowledgements We thank D. Biedenkopf for excellent technical assistance. This work was supported by Deutsche Forschungsgemeinschaft (DFG) project GRK2355 to KHK and AK. Fusarium culmorum KF350 was a gift of Dr. J. Chelkowski, Poznań, Poland. We thank Lisa Höfle for drawing the Fig. 1.

Author contributions K-H.K. wrote the manuscript; K-H.K and A.K. designed the study; E.S. conducted the experiments; K-H.K. and A.K. analyzed all data and drafted the figures. All authors reviewed the final manuscript.

Compliance with ethical standards The authors declare that the work is in compliance with ethical standards 
Competing financial interests The authors declare no competing financial interests. Work on Fusarium CYP3RNA (Koch et al. 2013 ) is subject of a patent application (WO2015004174A1).

Conflict of interest The authors declare no conflict of interests.

Research involving human participants and/or animals The authors declare that the manuscript does not contain research involving Human Participants and/or Animals.

Open Access This article is distributed under the terms of the Creative Commons Attribution 4.0 International License (http:// creativecommons.org/licenses/by/4.0/), which permits unrestricted use, distribution, and reproduction in any medium, provided you give appropriate credit to the original author(s) and the source, provide a link to the Creative Commons license, and indicate if changes were made.

\section{References}

Berridge, M. V., \& Tan, A. S. (1993). Characterization of the cellular reduction of 3-(4,5-dimethylthiazol-2-yl)-2,5-diphenyltetrazolium bromide (MTT): subcellular localization, substrate dependence, and involvement of mitochondrial electron transport in MTT reduction. Archives of Biochemistry and Biophysics, 303, 474-482.

Cai, Q., He, B., Kogel, K. H., \& Jin, H. (2018). Cross-kingdom RNA trafficking and environmental RNAi - nature's blueprint for modern crop protection strategies. Current Opinion in Microbiology, 46, 58-64.

Chen, Y., Gao, Q., Huang, M., Liu, Y., Liu, Z., Liu, X., \& Ma, Z. (2015). Characterization of RNA silencing components in the plant pathogenic fungus Fusarium graminearum. Scientific Reports, 5, 12500. https://doi.org/10.1038/srep12500.

Chen, W. X., Kastner, C., Nowara, D., Oliveira-Garcia, E., Rutten, T., Zhao, Y. S., Deising, H. B., Kumlehn, J., \& Schweizer, P. (2016). Host-induced silencing of Fusarium culmorum genes protects wheat from infection. Journal of Experimental Botany, 67, 4979-4991.

Cheng, W., Song, X. S., Li, H. P., Cao, L. H., Sun, K., Qiu, X. L., Xu, Y. B., Yang, P., Huang, T., Zhang, J. B., et al. (2015). Host-induced gene silencing of an essential chitin synthase gene confers durable resistance to Fusarium head blight and seedling blight in wheat. Plant Biotechnology Journal, 13, 1335-1345.

Deshmukh, S., \& Kogel, K. H. (2007). Piriformospora indica protects barley from root rot caused by Fusarium graminearum. Journal of Plant Diseases and Protection, 114, 263-268.

Fan, J., Urban, M., Parker, J. E., Brewer, H. C., Kelly, S. L., Hammond-Kosack, K. E., Fraaije, B. A., Liu, X., \& Cools, H. J. (2013). Characterization of the sterol 14alphademethylases of Fusarium graminearum identifies a novel genus-specific CYP51 function. New Phytologist, 198, 821835.

FAO (2012). World agriculture: Towards 2030/2050. The 2012 revision. Retrieved date| Accessed from Food and
Agriculture Organization of the United Nations website: http://www.fao.org.

FAO (2013). Fao statistical yearbook. World food and agriculture. Part 3: Feeding the World. Retrieved date| Accessed from Food and Agriculture Organization of the United Nations website: http://www.fao.org.

Ghag, S. B., Shekhawat, U. K., \& Ganapathi, T. R. (2014). Hostinduced post-transcriptional hairpin RNA-mediated gene silencing of vital fungal genes confers efficient resistance against Fusarium wilt in banana. Plant Biotechnology Journal, 12(5), 541-553.

Guo, Q., Liu, Q., Smith, N. A., Liang, G., \& Wang, M. B. (2016). RNA Silencing in plants: mechanisms, technologies and applications in horticultural crops. Current Genomics, 17, 476-489.

Koch, A., \& Kogel, K. H. (2014). New wind in the sails: improving the agronomic value of crop plants through RNAimediated gene silencing. Plant Biotechnology Journal, 12, 821-831.

Koch, A., Kumar, N., Weber, L., Keller, H., Imani, J., \& Kogel, K. H. (2013). Host-induced gene silencing of cytochrome P450 lanosterol C14-alpha-demethylase-encoding genes confers strong resistance to Fusarium species. Proceedings of the National Academy of Sciences of the United States of America, 110, 19324-19329.

Koch, A., Biedenkopf, D., Furch, A., Weber, L., Rossbach, O., Abdellatef, E., Linicus, L., Johannsmeier, J., Jelonek, L., Goesmann, A., Cardoza, V., McMillan, J., Mentzel, T., \& Kogel, K. H. (2016). An RNAi-based control of Fusarium graminearum infections through spraying of long dsRNAs involves a plant passage and is controlled by the fungal silencing machinery. PLoS Pathogens, 12, e1005901.

LaMonte, G., Philip, N., Reardon, J., Lacsina, J. R., Majoros, W., Chapman, L., Thornburg, C. D., Telen, M. J., Ohler, U., Nicchitta, C. V., et al. (2012). Translocation of sickle cell erythrocyte microRNAs into Plasmodium falciparum inhibits parasite translation and contributes to malaria resistance. Cell Host \& Microbe, 12, 187-199.

Liu, X., Yu, F., Schnabel, G., Wu, J., Wang, Z., \& Ma, Z. (2011). Paralogous cyp51 genes in Fusarium graminearum mediate differential sensitivity to sterol demethylation inhibitors. Fungal Genetics Biology, 48, 113-123.

Livak, K. J., \& Schmittgen, T. D. (2001). Analysis of relative gene expression data using real-time quantitative PCR and the 2(-Delta Delta C(T)) Method. Methods (San Diego, Calif.), $25,402-408$.

Machado, A. K., Brown, N. A., Urban, M., Kanyuka, K., \& Hammond-Kosack, K. (2018). RNAi as an emerging approach to control Fusarium Head Blight disease and mycotoxin contamination in cereals. Pest Management Science, 74, 790-799. https://doi.org/10.1002/ps.4748.

Majumdar, R., Rajasekaran, K., \& Cary, J. W. (2017). RNA Interference (RNAi) as a Potential Tool for Control of Mycotoxin Contamination in Crop Plants: Concepts and Considerations. Frontiers in Plant Science, 8, 200. https://doi.org/10.3389/fpls.2017.00200.

Melnyk, C. W., Molnar, A., \& Baulcombe, D. C. (2011). Intercellular and systemic movement of RNA silencing signals. The EMBO Journal, 30, 3553-3563. 
Mermigka, G., Verret, F., \& Kalantidis, K. (2016). RNA silencing movement in plants. Journal of Integrative Plant Biology, 58, $328-342$.

Molnar, A., Bassett, A., Hardcastle, T. J., Dunn, R., \& Baulcombe, D. C. (2010). Small silencing RNAs in plants are mobile and direct epigenetic modification in recipient cells. Science, 328, 872-875.

Niehl, A., Wyrsch, I., Boller, T., \& Heinlein, M. (2016). Doublestranded RNAs induce a pattern-triggered immune signaling pathway in plants. New Phytologist, 211(3), 1008-1019.

Niehl, A., Soininen, M., Poranen, M. M., \& Heinlein, M. (2018). Synthetic biology approach for plant protection using dsRNA. Plant Biotechnology Journal. https://doi. org/10.1111/pbi.12904 [Epub ahead of print].

Sarkies, P., \& Miska, E. A. (2013). Molecular biology. Is there social RNA? Science, 341, 467-468.

Wang, M., Weiberg, A., Lin, F.-M., Thomma, B. P. H. J., Huang, H. D., \& Jin, H. (2016). Bidirectional cross-kingdom RNAi and fungal uptake of external RNAs confer plant protection. Nature Plants, 2, 16151.

Wang, M., Weiberg, A., Dellota Jr., E., Yamane, D., \& Jin, H. (2017a). Botrytis small RNA Bc-siR37 suppresses plant defense genes by cross-kingdom RNAi. RNA Biology, 14, 421428.
Wang, B., Sun, Y. F., Song, N., Zhao, M. X., Liu, R., Feng, H., Wang, X. J., \& Kang, Z. S. (2017b). Puccinia striiformis f. sp tritici microRNA-like RNA 1 (Pst-milR1), an important pathogenicity factor of $P s t$, impairs wheat resistance to Pst by suppressing the wheat pathogenesis-related 2 gene. New Phytologist, 215, 338-350.

Weiberg, A., Wang, M., Lin, F. M., Zhao, H., Zhang, Z., Kaloshian, I., Huang, H. D., \& Jin, H. (2013). Fungal small RNAs suppress plant immunity by hijacking host RNA interference pathways. Science, 342, 118-123.

Weiberg, A., Bellinger, M., \& Jin, H. L. (2015). Conversations between kingdoms: small RNAs. Current Opinion Biotechnology, 32, 207-215.

Witwer, K. W., \& Hirschi, K. D. (2014). Transfer and functional consequences of dietary microRNAs in vertebrates: Concepts in search osf corroboration. Bioessays, 36(4), 394-406.

Zhang, L., Hou, D., Chen, X., Li, D., et al. (2012). Exogenous plant MIR168a specifically targets mammalian LDLRA P1: evidence of cross-kingdom regulation by microRNA. Cell Research, 22, 107-126.

Zhang, T., Zhao, Y. L., Zhao, J. H., Wang, S., Jin, Y., Chen, Z. Q., Fang, Y. Y., Hua, C. L., Ding, S. W., \& Guo, H. S. (2016). Cotton plants export microRNAs to inhibit virulence gene expression in a fungal pathogen. Nature Plants, 2, 16153. 